\title{
DETERMINANTES INDIVIDUAIS E DE CONTEXTO DA SIMPATIA PARTIDÁRIA NA AMÉRICA LATINA
}

\author{
Julian Borba
}

Universidade Federal de Santa Catarina (UFSC), Florianópolis (SC). E-mail: julian.borba@ufsc.br.

\section{Ednaldo Ribeiro}

Universidade Estadual de Maringá (UEM), Maringá (PR). E-mail: earibeiro@uem.br.

\section{Yan Carreirão}

Universidade Federal de Santa Catarina (UFSC), Florianópolis (SC). E-mail: yan.carreirao@ufsc.br.

\section{Eder Rodrigo Gimenes}

Universidade Estadual de Maringá (UEM), Maringá (PR). E-mail: ergimenes@uem.br.

DOI: $10.1590 / 339711 / 2018$

\section{Consideraçóes iniciais}

Pesquisas empreendidas em diversos países apontam para o crescente distanciamento entre partidos políticos e eleitorado, e destacam um cenário de crise e de declínio dessas instituiçóes nos Estados Unidos (Clarke e Stewart, 1998; Putnam, 2003; Dalton, McAllister e Wattenberg, 2003; Dalton, 2013) e em diversos países europeus (Whiteley e Seyd, 1998; 2002; Mair, 2003; Mair e Van Biezen, 2001; Dalton, McAllister e Wattenberg, 2003; Seyd e Whiteley, 2004; Freire, 2005; Morales, 2005; Scarrow e Gezgor, 2010; Witheley, 2011; Van Biezen, Mair e Poguntke, 2012).

As análises dessa natureza sobre a América Latina, região em que a maior parte dos países encontra-se em processo de consolidação democrática, são

Artigo recebido em 14/07/2016

Aprovado em 12/09/2017 destoantes. Enquanto alguns autores confirmam o desalinhamento partidário (Garretón, 1993; Baquero, 2000), outros afirmam que a ainda baixa institucionalização dos partidos faz parte da história política em contextos de fortalecimento democrático: trata-se de um processo de institucionalização e consolidação que náo deve ser interpretado como uma crise (Alcántara Sáez e Freidenberg, 2002).

Estudos recentes demonstram ser equivocada a afirmação de que há uma crise do partidarismo na região. Carreras, Morgenstein e Su (2013), baseados majoritariamente nos indicadores de volatilidade eleitoral, identificaram distintas tendências de relacionamento entre eleitores e partidos a partir da década de 1980. Já Albala e Vieira (2014), a partir de elementos contextuais, afirmam que as transformaçóes que afetam os partidos e sistemas partidários na América Latina são processuais e cíclicas e que, apesar da variação de a confiança nas referidas instituiçóes apresentar resultados pessimistas, os 
sistemas partidários na regiáo caminham rumo à institucionalização. Nesses termos, acreditamos que seja relevante analisar o partidarismo latino-americano, com vistas à identificação dos preditores do engajamento dos eleitores nessas instituiçóes.

Dessa forma, o objetivo deste artigo é identificar as bases individuais (sociodemográficas e atitudinais) e contextuais (como a idade do sistema democrático, o grau de fragmentação do sistema partidário, o tipo de sistema eleitoral e uma medida de natureza socioeconômica) da manifestação de simpatia partidária entre os eleitores latino-americanos. Para tanto, analisamos dados oriundos de pesquisas de opinião pública do Latin American Public Opinion Project (Lapop) e informaçóes coletadas junto a institutos internacionais de pesquisa, por meio de modelos de regressão hierárquicos.

Embora as hipóteses específicas sejam detalhadas mais à frente, cabe adiantar aqui algumas das preocupaçôes teóricas mais amplas de nosso estudo. O ponto de partida analítico está nas relaçôes entre as instituiçóes, as atitudes e o comportamento político. Ao inserirmos a dimensão contextual, exploramos, sobretudo, a tensão entre "engenharia" e "decantação". Com esses termos, Reis (2003) pretendeu caracterizar posiçóes no campo das propostas de reforma política no Brasil no início da década passada: de um lado, aqueles que defendem o papel das regras institucionais ("engenharia") na produçáo de resultados políticos concretos (e imediatos); de outro, os que advogam o elemento do aprendizado ("decantação"), ou seja, a ideia de que as instituiçóes operam dentro de determinado contexto, no qual "os produtos da ação política vêm a amadurecer com o transcurso do tempo, impregnando o contexto social geral e condicionando, em consequência, as percepçôes e disposições dos agentes em seu dia a dia" (Idem, p. 14).

$\mathrm{Na}$ perspectiva da "engenharia", a ênfase está no impacto que as instituiçóes podem ter sobre a capacidade de os eleitores formarem identidades sólidas com os partidos. Sob a perspectiva da "decantação", a formação de identidades partidárias poderia ser vista, em boa medida, como produto de processos de acúmulo de experiência eleitoral pelas geraçóes, especialmente de aprendizado a respeito do que representam os principais partidos políticos, aumentando a chance de que os eleitores se identifiquem com algum deles.

Seguindo essa discussão, vamos comparar, no contexto de novas democracias, com enfoque nas latino-americanas, a relevância, para a formação de identidades partidárias, do tempo de persistência do regime em contraste com as diversas configuraçóes internas que os sistemas políticos podem assumir, dependendo do sistema eleitoral e do grau de fragmentação do sistema partidário em cada país.

No que respeita às variáveis individuais, uma preocupação central é testar certos pressupostos de teorias que relacionam o envolvimento político (em nosso caso, especificamente a identificação com partidos) à disponibilidade de certos recursos por parte dos cidadãos (Verba, Schlozman e Brady, 1995), bem como à centralidade desses cidadãos na estrutura social (Reis, 2000). ${ }^{1}$

Além destas consideraçóes iniciais, o artigo dispóe ainda de quatro seçôes, nas quais apresentamos: uma breve revisão sobre a discussão teórica concernente à identificação partidária e resultados empíricos recentes sobre condicionantes do partidarismo; aspectos metodológicos de nossa análise e as hipóteses da pesquisa; os resultados decorrentes de tais testes; e consideraçóes finais acerca dos achados empíricos deste estudo.

\section{Partidarismo $^{2}$}

O conceito de identificação partidária ${ }^{3}$ tem sido central na literatura internacional sobre comportamento político (Mainwaring, 2001; Mainwaring e Torcal, 2005; Payne, 2007). Em termos gerais, os estudos apontam que o partidarismo tende a estruturar e dar significado "ao sistema de crenças individuais" (Dalton, McAllister e Wattenberg, 2003 , p. 295), da mesma maneira como a existência de vínculos dos eleitores com partidos políticos estrutura, em alguma medida, o voto dos indivíduos (Weisberg e Greene, 2003). ${ }^{4}$ Além disso, níveis elevados de partidarismo tendem a minimizar a volatilidade eleitoral e a contribuir para a estabilidade do sistema partidário (Dalton e Weldon, 2007; Mainwaring e Zoco, 2007). Nesses termos, Dalton, McAllister e Wattenberg (2003, p. 296) 
afirmam que "a conceptualização da identificação partidária é talvez um dos desenvolvimentos mais significativos na investigação da opinião pública”.

Em se tratando das teorias que se dedicam a analisar os determinantes da identificação dos eleitores com os partidos, a grande distinção se dá entre aquelas que interpretam a identificação como um fenômeno "identitário" (Green, Palmquist e Schickler, 2002), derivada do processo de socialização política, e aquelas que percebem a identificação partidária (IP) como um atalho informacional utilizado pelos eleitores, sendo produto da avaliação que os indivíduos fazem do desempenho dos partidos.

Quanto à primeira abordagem, a IP é interpretada como elemento central na definição do comportamento político dos indivíduos, sendo construída ao longo de seu processo de socialização. A identificação seria um componente central da própria constituição do indivíduo, uma "extensão do ego" (Rico, 2010). Tal modelo, conhecido como da Escola de Michigan (Campbell et al., 1960; Converse, 1969), entende que a IP se constituiria a partir de bases afetivas, equivalentes ao que, em outro campo, seriam as "identidades religiosas" (Rico, 2010). Ela começaria a se formar nos primeiros anos de vida, através da socialização familiar, e se manteria ao longo da vida, sendo, portanto, resistente a alteraçóes. A IP, de acordo com Converse (1969), se sedimentaria ao longo do tempo, à medida que as geraçóes acumulam experiência eleitoral (Rico, 2010). Destaque-se que, mesmo com as críticas que tal abordagem recebeu a partir da década de 1970, vários trabalhos recentes têm apresentado evidências empíricas relevantes sobre a importância da socialização política na explicação da IP (Miller; Shanks, 1996; Green; Palmquist; Schickler, 2002; Rico, 2010).

Já a abordagem da escolha racional entende que os atores políticos racionais buscam a maximização de suas satisfações subjetivas e se utilizam, para tanto, de atalhos de informação, elaborados a partir das imagens de partidos, candidatos e ideologias partidárias com a finalidade de diminuir os custos de obtenção e processamento de informaçóes políticas (Downs, 1957).

Fiorina (1981) apresenta uma perspectiva revisionista, segundo a qual, quando comparamos os efeitos da socialização dos indivíduos com aqueles derivados da avaliação da experiência acumulada pelo indivíduo como eleitor ao longo da vida adulta, esta última exerce peso maior sobre sua identificação partidária. Em sua interpretação, os eleitores emitem juízos de valor acerca das propostas e do desempenho partidários ao longo do tempo, de modo a balizar seu julgamento sobre a preferência partidária. Nesse sentido, o autor busca explicar tanto manifestaçóes de estabilidade quanto de alterações na identificação partidária do eleitorado, uma vez que o início da vida política dos eleitores é permeado por uma identificação partidária estável, construída por sua socialização prévia, ${ }^{5}$ a qual pode ser alterada ou mantida conforme os indivíduos adquirem experiência política e ainda de acordo com alterações em sua condição social e econômica, já que mudanças em tais padrôes interferem diretamente nos interesses dos cidadáos.

Se existem evidências empíricas bastante robustas das teorias acima para o contexto das democracias desenvolvidas, ainda sabemos muito pouco sobre como se estruturam e se alteram as relaçóes entre partidos e eleitores no contexto das jovens democracias, cujos sistemas partidários são, em geral, fracamente institucionalizados. Entre os poucos trabalhos que abordaram o assunto, temos Rico (2010) e Lisi (2014), para o contexto dos países do sul da Europa. Já no contexto da América Latina, os trabalhos que se dedicaram a conjuntos de países ${ }^{6}$ tratam de distintas abordagens. Mainwaring (2001) e Payne (2007) discorreram sobre a IP como indicador de institucionalização dos sistemas partidários. Moreno (2015) tratou da relação entre a intensidade do sentimento partidário e seus reflexos sobre atitudes e comportamentos políticos. Carreras, Morgenstein e Su (2013) e Albala e Vieira (2014) discutiram a existência de indícios do fenômeno do desalinhamento partidário na região.Porfim, Lupu (2015) e Gimenes (2015) se debruçaram sobre a verificação de determinantes do partidarismo. ${ }^{7}$ Considerando o objetivo deste artigo, nos concentraremos especificamente sobre os resultados do último conjunto de autores, bem como daqueles que abordaram a temática em países sul-europeus.

O estudo de Rico (2010), por meio de análise multinível, buscou testar principalmente as teses de Converse (1969) acerca dos efeitos geracionais 
sobre a IP e concluiu que tanto fatores individuais quanto contextuais influenciam na aquisição da identificação partidária. Entre as dimensóes de contexto, destacam-se especialmente a natureza e o grau de desenvolvimento democrático de cada país, assim como que níveis menores de volatilidade eleitoral e maiores índices de polarização ideológica influenciam positivamente a IP. Já fragmentação partidária apresentou efeitos não homogêneos entre os países, de modo que nas democracias mais jovens a maior fragmentaçáo aumenta a IP, enquanto nas antigas diminui. No âmbito das dimensões individuais, constatou-se o efeito da socialização sobre a IP, tanto em jovens quanto em velhas democracias da Europa. Contudo, há indícios de que o peso da experiência pessoal tende a diminuir nas democracias consolidadas.

O trabalho de Lisi (2014) comparou o efeito de variáveis relacionadas à socialização com aquele derivado da avaliação de desempenho (satisfação do eleitor com a economia e com os líderes partidários). Para o autor, a natureza do partidarismo nas democracias mais recentes é mais fortemente influenciada por esta última dimensão. Além disso, o partidarismo seria influenciado pelos tipos de partidos, sendo que os eleitores daqueles mais ideológicos são menos sensíveis às variações de curto prazo.

O estudo de Lupu (2015) buscou identificar, entre outras questóes, se os correlatos do partidarismo são semelhantes em democracias avançadas e novas, de modo que considerou duas hipóteses: 1) se as características individuais dos cidadãos que manifestam laços partidários são consistentes em distintos países, as origens de tais sentimentos podem estar relacionadas; 2) se os comportamentos políticos dos indivíduos que apresentam laços partidários se aproximam em velhas e novas democracias, as bases do partidarismo podem ser semelhantes nesses diferentes contextos.

O autor analisou a correlação entre partidarismo e um conjunto de características individuais, quais sejam: experiência democrática, extremismo ideológico, proximidade com algum partido, informação política e associativismo. Os resultados dos testes apontam que o perfil dos indivíduos que manifestam laços partidários na América Latina é semelhante àquele de democracias consolidadas: possuem maior idade e tempo de experiência democrática, são mais informados, mais instruídos e mais engajados na vida cívica. Ademais, quanto mais extremo seu posicionamento no espectro ideológico, maior a expectativa de partidarismo, sendo que eleitores de esquerda são mais propensos à manifestação de laços partidários, o que pode decorrer do contexto atual de predomínio de partidos com tal ideologia nos executivos nacionais.

Em termos de variáveis de contexto, Lupu (2015) identificou que em sistemas partidários mais fragmentados há menores índices de partidarismo, ao passo que tal variável se relaciona positivamente com elevaçóes dos indicadores de heterogeneidade étnica (proporção entre brancos e não brancos nas populaçôes nacionais), de institucionalização do sistema partidário e de polarização dos laços partidários manifestados pelos eleitores.

Já em Borba, Gimenes e Ribeiro (2015) foram analisados, com base em um modelo multinível, os determinantes da simpatia partidária e do ativismo partidário na América Latina. O estudo apontou para a validação de algumas teorias, como aquelas que problematizam os efeitos do ciclo de vida na participação em instituiçôes hierárquicas (Dalton, 2013). Por outro lado, não foram encontradas evidências de que a IP esteja relacionada à escolaridade, sempre destacada como uma das variáveis de maior importância nesses modelos explicativos. O mesmo fato ocorreu quanto à raça, normalmente associada a padróes persistentes de desigualdade na posse de recursos. Em compensação, foi confirmado o efeito significativo do sexo dos entrevistados, que pode ser analisado por esse viés da desigualdade. No terreno das atitudes, foram constatados os efeitos da eficácia política subjetiva e da disposição para buscar informaçóes, que indicam que mais do que recursos cognitivos (representados naquele modelo pela escolaridade), para o partidarismo importa uma orientação positiva de interesse pelos assuntos públicos, ou, nos termos propostos por Dalton (2013), uma "mobilização cognitiva".

O mais importante achado do estudo foi aquele relacionado aos efeitos das variáveis de contexto, em especial o efeito negativo do número efetivo de partidos políticos sobre a IP. Nesse sentido, a interpretação dos autores é de que sistemas mais com- 
plexos em termos da oferta de legendas partidárias tendem a dificultar o processo de escolha do eleitorado por conta da elevação dos custos de informação, que, no pior dos cenários, pode conduzir à nãodecisão (Borba, Gimenes e Ribeiro, 2015).

De modo a sistematizar o conhecimento acumulado sobre os preditores do partidarismo, Gimenes (2015) analisou, a partir de dados do Lapop para dois anos, 2008 e 2014, a influência de características sociodemográficas, atitudinais e estruturais sobre o enraizamento dos partidos políticos junto ao eleitorado. De maneira sucinta, seus resultados confirmaram a prevalência da sofisticação política como determinante do partidarismo, quando considerada em conjunto com variáveis sociodemográficas, bem como a relevância da persistência do regime democrático ao longo do tempo, em detrimento de aspectos políticos. Contudo, para além da verificação dos preditores da IP na região, o autor verificou que, a despeito das oscilaçóes em tal indicador, entre 2006 e 2014 o saldo de variação da IP foi positivo em dez países, com destaque ao Equador (elevação de23,4\%), e negativo em outros dez, sendo o índice de maior redução do partidarismo encontrado no Chile (11\%).

Em termos gerais, os estudos resenhados apresentam diagnósticos comuns sobre os efeitos da maioria das variáveis, entre as quais destacamos a relação positiva entre recursos individuais (busca por informação política, os níveis de associativismo, a condição masculina) e partidarismo, o qual também possui relação positiva com extremismo ideológico e posicionamento ideológico à esquerda.

Vimos, porém, diagnósticos discordantes em outras dimensões, como, por exemplo, o de que maior idade e maior tempo de exposiçáo ao regime democrático aumentam as chances do eleitor ter identificação partidária (Rico, 2010; Lupu, 2015). Os efeitos desta última dimensão foram parcialmente refutados por Lisi (2014) ao confrontar a idade e tempo de exposição ao regime com variáveis de avaliação de desempenho (satisfação do eleitor com a economia e com os líderes partidários). Da mesma forma, o efeito positivo da escolaridade verificado em Lupu (2015) não foi confirmado para o conjunto dos países analisados por Rico (2010). Continuando no campo das divergências, enquanto Lupu (2015) encontrou efeitos positivos da fragmentação partidária sobre a IP, o estudo de Rico (2010) relativizou tais conclusóes para o contexto das novas democracias europeias.

Tais divergências são suficientes para justificarmos o desenvolvimento de novos modelos analíticos que permitam uma análise mais integrada e aprofundada sobre os diferentes aspectos que podem exercer influência sobre a identificação partidária em contextos de jovens democracias. Nesse sentido, na próxima seção buscamos apresentar os elementos que compóem nosso modelo de análise.

\section{Metodologia e hipóteses}

A variável central da investigação é uma dimensão atitudinal, a simpatia partidária, tomada como proxy de identificação partidária. ${ }^{8}$ Nosso objetivo é verificar a possível influência de variáveis estruturais dos países analisados, especialmente aquelas relativas a seus sistemas partidários, bem como de variáveis atitudinais dos eleitores (nível individual) sobre a simpatia manifestada pelos indivíduos em relação a partidos.

O modelo de análise escolhido foi a regressão logística binária multinível. Com esse procedimento é possível incorporar em um único modelo tanto variáveis de atributos sociais e atitudinais dos indivíduos quanto características estruturais de natureza social, política e, mais especificamente, eleitoral de cada nação incluída na pesquisa (Raudenbush e Bryk, 2002).

Como variáveis de nível individual foram selecionadas medidas relativas aos seguintes atributos sociais, atitudes e valores: sexo, idade, escolaridade, busca por informação, eficácia política subjetiva, avaliação de governo e grau de extremismo ideológico. Optamos por utilizar os dados da pesquisa do Lapop de 2014 por sua abrangência, já que cobre mais de duas dezenas de países na América Latina e Caribe. Para o segundo nível, as variáveis selecionadas foram: taxa de crescimento do produto interno bruto (PIB) per capita, idade da democracia, tipo de sistema eleitoral e número efetivo de partidos políticos (NEP) nas Câmaras. No início da seção de resultados apresentamos estatísticas descritivas dessas 
medidas de nível macro em suas escalas originais, todavia, para a sua inclusáo nos modelos multivariados optamos pela padronização em escalas de 0 a 1 , de modo a facilitar a comparação dos seus efeitos. ${ }^{9}$

Cada uma dessas variáveis foi inserida para viabilizar o teste de algumas hipóteses ou expectativas iniciais derivadas da literatura sobre identificação partidária, em especial, das divergências elencadas acima nos estudos sobre identificação partidária em novas democracias.

Ao inserir o sexo dos entrevistados, o trabalho dialoga com diagnósticos acerca da desigualdade política entre homens e mulheres (Heidar, 2006; Norris, 2011; Whiteley, 2011; Van Biezen, Mair e Poguntke, 2012). Nossa expectativa inicial era verificar um maior percentual de homens simpáticos a algum partido, devido especialmente à distribuição desigual do recurso "tempo" entre os gêneros. Sabe-se que a inserção das mulheres no mercado de trabalho moderno não foi acompanhada de liberação de suas atribuiçóes domésticas de cuidado com o lar e a prole, o que as leva recorrentemente à dupla jornada de trabalho, sendo plausível supor que essa sobrecarga de atribuiçóes reduz o tempo disponível das mulheres para se informar e avaliar as atividades políticas correntes, com reflexo na capacidade de formar identificações com partidos.

Quanto à variável idade, desde o seminal estudo de Converse (1969) ela tem sido analisada como indicador central no processo socialização política, uma vez que propicia às geraçóes acumular experiência eleitoral (Rico, 2010). Lupu (2015) aponta uma literatura que sustenta que os vínculos partidários se fortalecem à medida que os eleitores ganham experiência, atualizando e fortalecendo sua avaliação a respeito dos partidos, o que comprovou empiricamente em sua análise de dados do Lapop entre 2006 e 2012 para um conjunto de dezoito países latino-americanos mais os Estados Unidos.

Outra hipótese, derivada ainda da preocupação geral com os efeitos da distribuição desigual de recursos sociais e econômicos, relaciona a escolaridade dos eleitores com a probabilidade de que formem simpatia com partidos políticos. No modelo do voluntarismo cívico de Verba, Schlozman e Brady (1995), a escolaridade é um atributo fortemente associado ao desenvolvimento de habilidades cívi- cas, o que torna possível derivar a expectativa de encontrar maior partidarismo entre os eleitores de maior escolaridade.

Passando às variáveis atitudinais e valorativas, as hipóteses são bem menos diretas e inequívocas, já que a literatura especializada tem se debruçado de maneira incipiente sobre a realidade latino-americana e os achados internacionais dificilmente podem ser aplicados de forma automática às jovens democracias da regiáo. Se considerarmos a relativa novidade dessa forma de regime político entre os países aqui analisados, uma vez que a maioria das naçóes fez suas transiçóes no que Huntington (1994) chama de terceira onda de democratização, seria possível esperar que o apoio à democracia fosse acompanhado de maior adesão às instituiçóes fundamentais desse tipo de regime, como os partidos políticos. Todavia, a hipótese alternativa $\mathrm{da}$ "cidadania crítica", proposta para os contextos das democracias consolidadas, precisa ser considerada. Pesquisadores como Norris (1999) e Inglehart e Welzel (2009) têm defendido que entre o público de diferentes naçóes economicamente desenvolvidas o desencanto com as instituiçóes políticas tradicionais tem ocorrido em paralelo ao fortalecimento de posturas pró-democracia. $\mathrm{O}$ cidadão crítico em relação ao funcionamento dos partidos e das demais estruturas representativas não seria, portanto, um inimigo ou perigo para a democracia. A ocorrência desse tipo de cidadão, entretanto, é resultado de níveis consideráveis de sofisticação política, ligados a condiçóes sociais e econômicas favoráveis e também ao longo convívio com o regime democrático. Nesse sentido, buscamos identificar os efeitos da eficácia política individual e da busca por informações sobre a identificação partidária.

No caso do sentimento de eficácia subjetiva, supomos que aqueles que se enxergam como relevantes em termos políticos tenderiam a manifestar maior propensão ao envolvimento com os partidos, incluindo o desenvolvimento de simpatias. Utilizando tal medida, conforme estudo seminal de Almond e Verba ([1963] 1989), Dalton (2013) identificou no eleitorado norte-americano que o sentimento de efetividade da participação na política se relaciona à cognição, independente de condiçóes financeiras. Entendemos que essa autoavaliação positiva sobre a 
capacidade de influenciar decisóes de natureza política favorece o cálculo sobre os custos e benefícios relacionados à identificação partidária. ${ }^{10}$

Outra variável individual identifica a frequência de busca por informação dos entrevistados. Utilizamos tal medida como proxy de sofisticação política, apoiados no argumento de Dalton e Wattenberg (2003) e de Fonseca (2013) de que a referida variável demonstra o interesse dos indivíduos por assuntos em geral, incluídos aqueles relacionados à vida pública, de modo a contribuir, em alguma medida, com o desenvolvimento da capacidade do eleitor de avaliar o jogo político. Segundo Dalton (2013), o partidarismo é uma forma de mobilização à qual se relacionam, entre outros fatores, maior conexáo com assuntos políticos, por conta da intensidade ou frequência de acesso às informaçóes. Nesse sentido, nossa expectativa era encontrar efeitos positivos nessa medida, ou seja, que aqueles que acessam maior volume de informaçôes possuam maior probabilidade de simpatizar com algum partido. Para tanto, usamos uma medida exigente, que distingue os indivíduos entre aqueles que buscam informaçóes diariamente dos demais (variável binária).

Cabe indicar que as variáveis acima (sexo, idade, escolaridade) servem também para testar a hipótese relacionada à teoria da centralidade (Reis, 2000), de que cidadáos que ocupam posiçóes mais "centrais" na estrutura social tendem a ter maior participação política (ou, no nosso caso, tendem a ter maior probabilidade de desenvolver identificação com partidos).

A avaliação que os eleitores fazem do governo em exercício pode ter influência sobre a probabilidade de os eleitores manifestarem simpatia por partidos (e, portanto, nas flutuaçóes das taxas agregadas, por país, de simpatia partidária ao longo do tempo). Tomando a tese de Fiorina (1981), de que as identificaçóes partidárias resultam principalmente da avaliação que os eleitores fazem do desempenho dos partidos ao longo do tempo, pode-se esperar que em momentos em que o governo esteja mal avaliado: deve declinar a simpatia pelo(s) partido(s) do governo ${ }^{11}$ e, se nenhum partido de oposição se beneficiar disso, tende a diminuir a simpatia partidária como um todo. ${ }^{12}$
Lupu (2015) afirma que os posicionamentos ideológicos dos eleitores têm influência sobre seus vínculos com os partidos políticos, já que eleitores tendem a se identificar com os partidos cujas posiçôes ideológicas são mais próximas das suas. Se isso vale para o conjunto de eleitores, o vínculo entre eleitores ideologicamente mais extremistas com os partidos que são próximos a eles seria mais forte do que para os eleitores centristas. Nesse sentido, consideramos os eleitores em cada país que se situam nos extremos da escala esquerda-direita ( 0 e $1 ; 9$ e 10) para a composição do indicador de extremismo ideológico.

No nível das unidades nacionais, a primeira variável inserida foi o PIB per capita. Assim como os recursos materiais e cognitivos no nível individual estáo associados ao maior envolvimento político, é plausível supor que a melhoria nas condiçóes materiais gerais de um país afete positivamente a identificação partidária dos cidadãos. No caso específico desta pesquisa, a melhoria do indicador de desenvolvimento econômico conduziria à maior probabilidade de simpatizar com partidos. Em contraposição a essa expectativa, entretanto, é preciso considerar os efeitos das condiçóes econômicas sobre o desenvolvimento da chamada cidadania crítica (Norris, 2011) e o possível afastamento das instituições tradicionais de representação. Analisando principalmente os contextos dos países economicamente desenvolvidos e com longo histórico democrático, Norris tem associado a melhoria geral nas condiçóes de existência ao desenvolvimento de cidadãos cada vez mais interessados na sua autoexpressão e em formas mais autônomas de manifestação política. Esses novos interesses estariam conduzindo à crítica das instituiçóes políticas organizadas de maneira hierárquica, como os partidos políticos. É claro que as condiçóes para o desenvolvimento de tal sofisticação política, que fundamenta a postura crítica, dificilmente podem ser verificadas entre os países latino-americanos, mas ainda assim é necessário considerar a hipótese alternativa do efeito negativo do desenvolvimento econômico sobre o partidarismo em nossos modelos.

A fim de levar em consideração o já mencionado contraste entre "engenharia" e "decantação", incluímos ainda em nossa análise diversas variáveis relacionadas a características relevantes dos sistemas 
partidários. Entre essas, uma que parece fortemente associada ao grau de institucionalização dos partidos e do sistema partidário é a idade do sistema democrático. Em geral, a idade dos partidos existentes tende a ser fortemente correlacionada com o tempo em que a democracia está em vigor em cada país. Adicionalmente, espera-se que haja uma tendência de associação positiva entre a idade dos partidos e a probabilidade de que os eleitores se identifiquem com eles. Mainwaring (2001), por exemplo, apontou que a volatilidade eleitoral é bem maior em democracias mais recentes, comparativamente às democracias consolidadas, de modo que se manifesta mais acentuadamente onde as identificaçóes partidárias são frágeis.

Há, porém, algumas tendências que podem atenuar aquela expectativa. Lupu (2014) afirma que tem ocorrido um processo de diluição das "marcas partidárias" (party brands) em vários países da América Latina nas décadas recentes. Partidos que por décadas eram competitivos tornam-se irrelevantes eleitoralmente em pouco tempo. ${ }^{13}$ Em países em que esse processo aconteceu com partidos importantes, talvez a associação entre idade da democracia (e dos partidos) e taxa de simpatia partidária seja menos significativa. Outro aspecto que pode afetar aquela associação é a maior ou menor facilidade institucional para a criação de partidos. No Brasil, por exemplo, Carreirão (2014) aponta a existência de incentivos institucionais para a criação de novos partidos. ${ }^{14}$ Assim, mesmo que uma democracia seja mais longeva que outra, caso nesta última não haja incentivos para a criação de novos partidos, podem ser estabelecidos vínculos mais duradouros entre eleitores e partidos. Diante dessas possibilidades, nossa expectativa, seguindo a perspectiva mais tradicional, era de que quanto mais antiga uma democracia na América Latina, maior a probabilidade de os eleitores formarem simpatia por algum partido. Tomamos os dados de Péres-Liñán e Mainwaring (2013) sobre o primeiro ano do regime democrático mais recente em cada país como referência para o cálculo da idade da democracia, considerando 2013 como data final para esse cálculo.

Dentre as variáveis institucionais que podem influenciar a formação de simpatia partidária, destaca-se também o sistema eleitoral vigente em cada país. Há uma vasta literatura que discute os possíveis efeitos dos sistemas eleitorais sobre os partidos (o grau em que a organização partidária é fortaleci$\mathrm{da}$, em que o voto pessoal ou partidário é estimulado etc.). Um trabalho dos mais influentes nesse debate é o de Carey e Sugar (1995), que apresenta entre suas proposiçóes a de que quando os líderes exercem grande controle sobre a ordem em que os candidatos de seu partido serão beneficiados pelo voto dos eleitores, o incentivo para um político cultivar uma reputação individual é minimizado, prevalecendo o interesse dos membros do partido em formar uma reputação partidária; inversamente, quando aquele controle é fraco, as reputaçóes pessoais passam a ter mais valor. Embora os autores mencionem outros aspectos, nos interessa distinguir, de um lado, os sistemas proporcionais de lista aberta, em que há maior incentivo para o cultivo de reputaçóes pessoais (o que reduz o incentivo ao eleitor para formar identificação ou simpatia partidária), e, de outro, os sistemas proporcionais de lista fechada, em que os políticos têm interesse em cultivar uma reputação partidária e os eleitores têm incentivos para votar partidariamente. Nessa ótica, os sistemas majoritários com candidato único por distrito (Single Member District - SMD) se aproximam mais dos sistemas de lista fechada, já que o partido, ao escolher um único candidato para concorrer no distrito, delimita a escolha dos eleitores, além do que "a sorte do candidato depende da habilidade de todo o partido atrair votos (para o candidato)" (Carey e Sugar, 1995, p. 421).

Contudo, ressaltamos que não há consenso na literatura em relação às proposições de Carey e Sugar (1995). Klein (2007), analisando dados referentes a 27 países - produzidos por Norris (2002) e pelo Comparative Study of Electoral Systems(CSES) para o período 1996-2001 -, mostra haver grande variação interna nas taxas de identificação partidária para cada grupo de países, segundo o tipo de sistema eleitoral adotado (majoritário, proporcional de lista fechada, de lista aberta ou misto). Samuels (1997), examinando o caso brasileiro, mostra que as estratégias partidárias podem atenuar os efeitos do sistema eleitoral e, nesse sentido, aponta como o Partido dos Trabalhadores (PT) pôde "estruturar incentivos proporcionados aos seus candidatos de 
modo a fazer face à propensão do sistema eleitoral para o individualismo". De toda forma, considerando a influência do trabalho de Carey e Sugar (1995), optamos por testar a hipótese baseada em suas proposiçóes, assumindo para os sistemas de lista aberta o valor 0 (menor incentivo ao voto partidário e, portanto, à formação de simpatia partidária) e para os demais sistemas o valor 1 (maior incentivo ao voto partidário). No caso dos sistemas mistos, essa decisão se deveu ao fato de que na parte proporcional deles (para os três países que adotam sistemas mistos), os eleitores votam em listas fechadas (Quadro A, anexo).

O grau de fragmentação dos sistemas partidários pode também afetar a capacidade de os eleitores se identificarem com os partidos. A fragmentação partidária é uma medida do grau em que o voto (ou as cadeiras parlamentares) é dividido entre diferentes partidos em um país. É mais difícil para os eleitores em países com sistemas partidários muito fragmentados acompanhar a trajetória e o desempenho dos distintos partidos e eventualmente estabelecer algum tipo de identificação com algum deles. Além disso, em sistemas muito fragmentados tendem a se formar coalizóes governamentais maiores, dificultando a tarefa dos eleitores de associar o desempenho de governos a determinados partidos (Lupu, 2015). Nossa expectativa, então, era a de que quanto maior a fragmentação, menor a probabilidade de os eleitores manifestarem simpatia por algum partido, como verificamos anteriormente num modelo hierárquico com distinta composição de variáveis independentes. Utilizamos como indicador do grau de fragmentação dos sistemas partidários o número efetivo de partidos políticos (NEP), medida de fragmentação que "conta" os partidos existentes num sistema partidário, ponderando-os por seu peso eleitoral ou segundo a proporção de cadeiras ocupadas no Parlamento (Laakso e Taagepera, 1979).

\section{Resultados}

A Tabela 1 apresenta uma síntese das informaçóes relativas aos países para cada uma das variáveis de contexto apresentadas na seção anterior. Em ter- mos gerais, podemos observar significativa variabilidade entre as características nacionais na região, começando pelo indicador econômico, já que são registrados casos de reduzido crescimento, como no México e na Venezuela, enquanto Panamá, Bolívia e Paraguai apresentaram sinal de vitalidade no momento analisado. Merece destaque este último país, por ter apresentado em 2013 crescimento de $14,2 \%$ no seu PIB, enquanto seus vizinhos Brasil e Argentina registraram modestos 2,5 e 2,9\%, respectivamente.

Quanto à idade da democracia, existem diferenças significativas entre os países, uma vez que há, de um lado, unidades nacionais onde o regime ainda não completou três décadas ininterruptas desde seu estabelecimento ou retomada (como Chile, México, Panamá e Paraguai) e, de outro, aqueles onde a democracia persiste há mais de meio século (casos de Venezuela, Colômbia e Costa Rica). Na dimensão política, as diferenças também são expressivas, a começar pelo NEP, já que observamos casos de baixíssima fragmentação, como Nicarágua, Bolívia e Venezuela, e também casos de alta fragmentação, como Chile, Colômbia e Brasil, este último registrando impressionantes 10,36 partidos efetivos. A variação passa a ser menor ao considerarmos os indicadores mais abrangentes sobre a longevidade da democracia.

$\mathrm{Na}$ Tabela 2 são apresentadas informaçóes descritivas sobre as variáveis individuais, também para cada país. Na primeira coluna está o percentual de simpatia partidária, nossa variável dependente, indicando variabilidade bastante expressiva. Guatemala e Chile são os dois países que apresentam os menores valores, respectivamente 11,4 e 13,1\%. Costa Rica e Uruguai, por outro lado, são os países que ocupam as melhores posições, registrando 60 e $67,4 \%$. Uma quantidade significativa de países (sete) se encontra em uma zona intermediária que vai de 40 a $50 \%$.

A distribuição amostral entre os sexos e faixas etárias dispensa comentários adicionais. É possível observar variação expressiva na escolarizaçáo, representada pelo percentual de pessoas com educaçáo superior. O grupo é bem mais homogêneo no que diz respeito ao indicador de eficácia política subjetiva, com a maioria dos países apresentando percen- 
Tabela 1

Informações Descritivas sobre Características Nacionais (América Latina)

\begin{tabular}{lllll}
\hline País & $\begin{array}{l}\text { Crescimento do } \\
\text { PIB }\end{array}$ & $\begin{array}{l}\text { Idade da } \\
\text { democracia }\end{array}$ & Sistema eleitoral & $\begin{array}{l}\text { Fragmentaçáo } \\
\text { (NEP) }\end{array}$ \\
\hline Argentina & 2,9 & 31 & 1 & 4,26 \\
\hline Bolívia & 6,8 & 32 & 1 & 1,85 \\
\hline Brasil & 2,5 & 29 & 0 & 10,36 \\
\hline Chile & 4,1 & 24 & 0 & 5,64 \\
\hline Colômbia & 4,7 & 56 & 1 & 5,07 \\
\hline Costa Rica & 3,5 & 65 & 1 & 3,90 \\
\hline Equador & 4,6 & 36 & 0 & 3,75 \\
\hline El Salvador & 1,7 & 30 & 1 & 3,19 \\
\hline Guatemala & 3,7 & 28 & 1 & 4,14 \\
\hline Honduras & 2,6 & 32 & 0 & 2,30 \\
\hline México & 1,1 & 26 & 1 & 3,56 \\
\hline Nicarágua & 4,6 & 30 & 1 & 1,80 \\
\hline Panamá & 8,4 & 24 & 0 & 3,69 \\
\hline Paraguai & 14,2 & 25 & 1 & 3,43 \\
\hline Peru & 5,8 & 34 & 0 & 3,97 \\
\hline Uruguai & 4,4 & 29 & 1 & 2,65 \\
\hline Venezuela & 1,3 & 55 & 1 & 1,97 \\
\hline
\end{tabular}

Notas/Fontes: Crescimento do PIB per capita registrado em 2013 (Databank/World Bank); Polity IV de 2013 (Center of Systemic Peace); idade da democracia (em anos) até 2013 (Pérez-Liñán; Mainwaring, 2013); sistema eleitoral vigente em 2013, com 0 = proporcional/lista aberta e 1 = lista fechada/maioria simples/misto (Nicolau, 2012; Political Database of the Americas); fragmentação (Power, 2015).

tuais entre 30 e $50 \%$, o que também pode ser dito em relação às variáveis sobre busca de informação política e avaliação presidencial. Por fim, é verificada heterogeneidade na medida de extremismo ideológico, já que registramos não só países com contingente reduzido, como Peru (15,3\%) e Argentina $(17,1 \%)$, mas também com metade da população nos extremos de autoidentificação, como a Nicarágua $(50,9 \%)$.

Como nossa intenção é avaliar os efeitos de variáveis nacionais e individuais sobre a manifestação de simpatia, optamos por um modelo estatístico multinível generalizado para variáveis com distribuição de Bernoulli, já que comporta apenas dois valores: 0 = não e 1 = sim (Raudenbush e Bryk, 2002). ${ }^{15}$
Apesar da Tabela 2 indicar a existência de considerável variaçấo em termos de simpatia entre os países, para verificar de forma mais consistente a natureza multinível desse fenômeno conduzimos um modelo nulo inicial, sem variáveis de nível nacional ou individual. ${ }^{16}$ Com isso, considerando o conjunto dos países, a média do log da razão de chance de manifestar simpatia partidária foi estimada em -0,659 e a variância em 0,535 (Tabela 3). A partir deste último valor calculamos o coeficiente de correlação intraclasse (Snijders e Bosker, 1999) de 0,1398 , indicando que aproximadamente $14 \%$ da variação na simpatia partidária se deve a características nacionais. A razão de probabilidade estatística para o teste de hipótese nulo (de que a variân- 


\section{Tabela 2}

Informaçóes Descritivas sobre Características Individuais (América Latina, 2014)

\begin{tabular}{lllllllll}
\hline País & IP & Sexo & Idade & Escol. & EPS & Inf. & Aval. & Extr. \\
\hline Argentina & 25,7 & 48 & 42,1 & 21,5 & 44,5 & 69,4 & 2,85 & 17,1 \\
\hline Bolívia & 25,6 & 49,4 & 39,6 & 25,7 & 28,4 & 62,5 & 3,52 & 19,1 \\
\hline Brasil & 23 & 49,9 & 39,6 & 8,3 & 31,6 & 71,3 & 3,10 & 26,5 \\
\hline Chile & 13,1 & 48 & 49,4 & 21,3 & 44,1 & 73,5 & 3,48 & 25,9 \\
\hline Colômbia & 28,2 & 50,2 & 38,0 & 15,5 & 34,8 & 69,9 & 3,04 & 31,9 \\
\hline Costa Rica & 67,4 & 48,9 & 42,7 & 11,7 & 39,3 & 66,4 & 2,48 & 28,7 \\
\hline Equador & 45 & 49,9 & 39,4 & 20 & 38,2 & 58,6 & 3,86 & 28,4 \\
\hline El Salvador & 44,7 & 44,6 & 40,6 & 13,4 & 46,7 & 66,7 & 3,7 & 39,1 \\
\hline Guatemala & 11,4 & 49,9 & 39,4 & 2,4 & 25,8 & 41,3 & 3,15 & 27,3 \\
\hline Honduras & 40 & 50,1 & 39,3 & 6 & 43,4 & 62,1 & 3,64 & 42,4 \\
\hline México & 27,4 & 50 & 40,8 & 14,7 & 34,4 & 47,9 & 2,78 & 34,4 \\
\hline Nicarágua & 46,9 & 50 & 39,7 & 10,9 & 38,3 & 56,9 & 3,67 & 50,9 \\
\hline Panamá & 45,6 & 49,7 & 38,6 & 21,9 & 37,4 & 57,6 & 3,49 & 29,5 \\
\hline Paraguai & 40,3 & 49,8 & 37,4 & 21,2 & 33,4 & 57,7 & 3,23 & 42,12 \\
\hline Peru & 19,2 & 49,9 & 40,0 & 29,9 & 32,7 & 67,6 & 2,91 & 15,3 \\
\hline Uruguai & 60 & 47,4 & 46,5 & 18,9 & 48,2 & 79,6 & 3,47 & 29,6 \\
\hline Venezuela & 45,5 & 50 & 40,6 & 25,3 & 53,2 & 56,5 & 2,37 & 41,5 \\
\hline Notas: IP & & & & & & & &
\end{tabular}

Notas: IP = \% de simpatia partidária; Sexo = \% de homens; Idade= anos de vida (média); Escol. = escolaridade (\% com ensino superior completo); EPS = eficácia política subjetiva (\% de alta); Inf. = acesso à informação (\% de acesso diário); Aval. = avaliação de governo (média, em uma escala de 1 a 5 , em que 1 é "muito ruim" e 5 é "muito boa"); Extr. = extremismo ideológico (\% de indivíduos que se posicionaram nos pontos $0,1,9$ e 10).

Fonte: Lapop (2014).

cia entre os países é igual a 0) pode ser calculada com a comparação desse resultado com aquele que seria obtido com um modelo equivalente contendo apenas as variáveis de nível individual, ou seja, sem os efeitos aleatórios do nível dos países. O resultado da subtração das razões de chance dos modelos é $-1323,926$, então a razão de probabilidade pode ser obtida com $\left(-2^{*}(-1323,93)\right)=2647,85$ com 1 grau de liberdade, o que indica claramente variância diferente de 0 entre os países.

Confirmada a pertinência da modelagem multinível, especificamos uma equação de efeitos fixos contendo apenas as variáveis de nível individual, relativas a atributos socioeconômicos e também atitudes políticas (Tabela 4, coluna "Efeitos fixos"). É possível perceber mudança na variância no $\log \mathrm{da}$ probabilidade de simpatia (de 0,535 para 0,553 ) com a inclusão das variáveis individuais, o que indica variação nessas medidas entre os países, conforme a Tabela 3 informou. Apesar de reportarmos anteriormente as informaçóes descritivas dessas variáveis nas suas escalas originais, para possibilitar a comparação dos seus efeitos nos modelos que seguem as suas escalas foram padronizadas para variarem de 0 a 1 .

Como medida de ajuste dos modelos, utilizamos o Akaike's Information Criterion (AIC), que tem sido empregado com relativa frequência em modelos multiníveis. Diferentemente do R-quadrado empregado em modelos lineares, os valores de AIC 
Tabela 3

Modelo Nulo para Identificação Partidária (América Latina, 2014)

\begin{tabular}{ll}
\hline Intercepto & $-0,659$ \\
\hline Variância & 0,535 \\
\hline AIC & 32331,8 \\
\hline N nível 1 & 26956 \\
\hline N nível 2 & 17 \\
\hline
\end{tabular}

Fonte: Lapop (2014).

de modelos isolados não são informativos, já que não podem ser interpretados como indicador preciso da capacidade explicativa do conjunto dos preditores incluídos na equação. Sua utilidade reside na comparação de modelos rivais utilizando um mesmo conjunto de dados e uma mesma variável dependente, sempre conduzindo a seleção do melhor modelo entre os apresentados (Burnham e Anderson, 2002; McCullagh e Nelder, 1989). De forma bastante simplificada, valores menores correspondem a modelos comparativamente melhores e adicionalmente pode-se calcular o delta para AIC () e o peso dessa medida para cada modelo. Como seria esperado, esse modelo contendo variáveis de nível individual é melhor do que o nulo, que comportava apenas os efeitos aleatórios de nível nacional.

Os coeficientes de cada preditor indicam o seu impacto médio entre os países, já que se trata de um modelo com efeitos fixos. Todos os efeitos estatisticamente significativos foram positivos, indicando que as variáveis introduzidas no modelo elevam a probabilidade de manifestação de identificação partidária. $\mathrm{O}$ efeito da variável sexo $(\mathrm{B}=$ $0,11^{17}$ e $\operatorname{Exp}=1,11^{18}$ ) indica que um homem tem $11 \%$ mais chance de manifestar identificação partidária do que uma mulher. Com a padronização das variáveis (0-1) a diferença entre o entrevistado mais jovem e o mais velho é de mais de $260 \%$ ( $B=1,29$ e $\operatorname{Exp}=3,63)$, enquanto o efeito da escolaridade $(\mathrm{B}=0,18$ e $\operatorname{Exp}=1,20)$ indica que a diferença na probabilidade entre os extremos dessa escala é de $20 \%$. O sentimento de eficácia política subjetiva (B $=0,43$ e $\operatorname{Exp}=1,54)$ indica que aqueles que se sen- tem relevantes em termos políticos têm 54\% mais chance de manifestar simpatia por algum partido. Aqueles que registram a pontuação mais elevada na escala de busca por informação $(B=0,29$ e Exp $=1,34)$, por sua vez, têm chance $34,3 \%$ maior do que aqueles com a menor pontuação. $\mathrm{O}$ efeito da variável de avaliação de governo $(\mathrm{B}=1,22$ e Exp $=3,39)$ indica que a diferença na probabilidade de manifestação de identificação entre os extremos da escala é de mais de $230 \%$. Por fim, a variável sobre extremismo ideológico não se mostrou um preditor relevante nesse modelo.

A opção por um modelo multinível, todavia, torna possível verificar se os efeitos das variáveis individuais são diferentes entre os diversos países. Para isso, especificamos um modelo de efeitos aleatórios contendo, ainda, apenas os preditores de nível individual (Tabela 4, coluna "Efeitos Aleatórios").

Nesse novo modelo os efeitos sofrem pequenas alterações, quase todas com elevaçóes. A exceção fica por conta da avaliaçáo de governo, que sofre uma sutil redução. A medida de ajuste do modelo também apresenta melhora, já que se observa redução no valor do AIC. O mais importante, entretanto, é identificar o quanto esses efeitos diferem entre os países, o que pode ser analisado pela variância de cada um deles. Idade, escolaridade e avaliação de governo são as três medidas que apresentam maior variabilidade de efeitos entre os países, enquanto sexo, eficácia e busca por informação apresentaram impactos relativamente homogêneos.

O próximo modelo especificado inclui as variáveis de nível nacional e testa, fundamentalmente, os efeitos da durabilidade da democracia (em termos de anos ininterruptos) e as características institucionais como fragmentação do sistema partidário e o sistema eleitoral (lista fechada ou não). Além disso, em razão da relevância que as variáveis sobre recursos têm assumido para uma ampla variedade de comportamentos e atitudes, incluímos também o PIB per capita. Para possibilitar alguma comparabilidade dos efeitos optamos por padronizar essas medidas em uma escala de 0 a 100.

Os resultados exibidos na Tabela 5 (coluna "Sem interaçôes") indicam sutil melhora na medida de ajuste do modelo, na comparação com o modelo anterior contendo apenas as variáveis de 
Tabela 4

Preditores (Efeitos Fixos e Aleatórios) de Nível Individual para a Identificaçáo Partidária (América Latina, 2014)

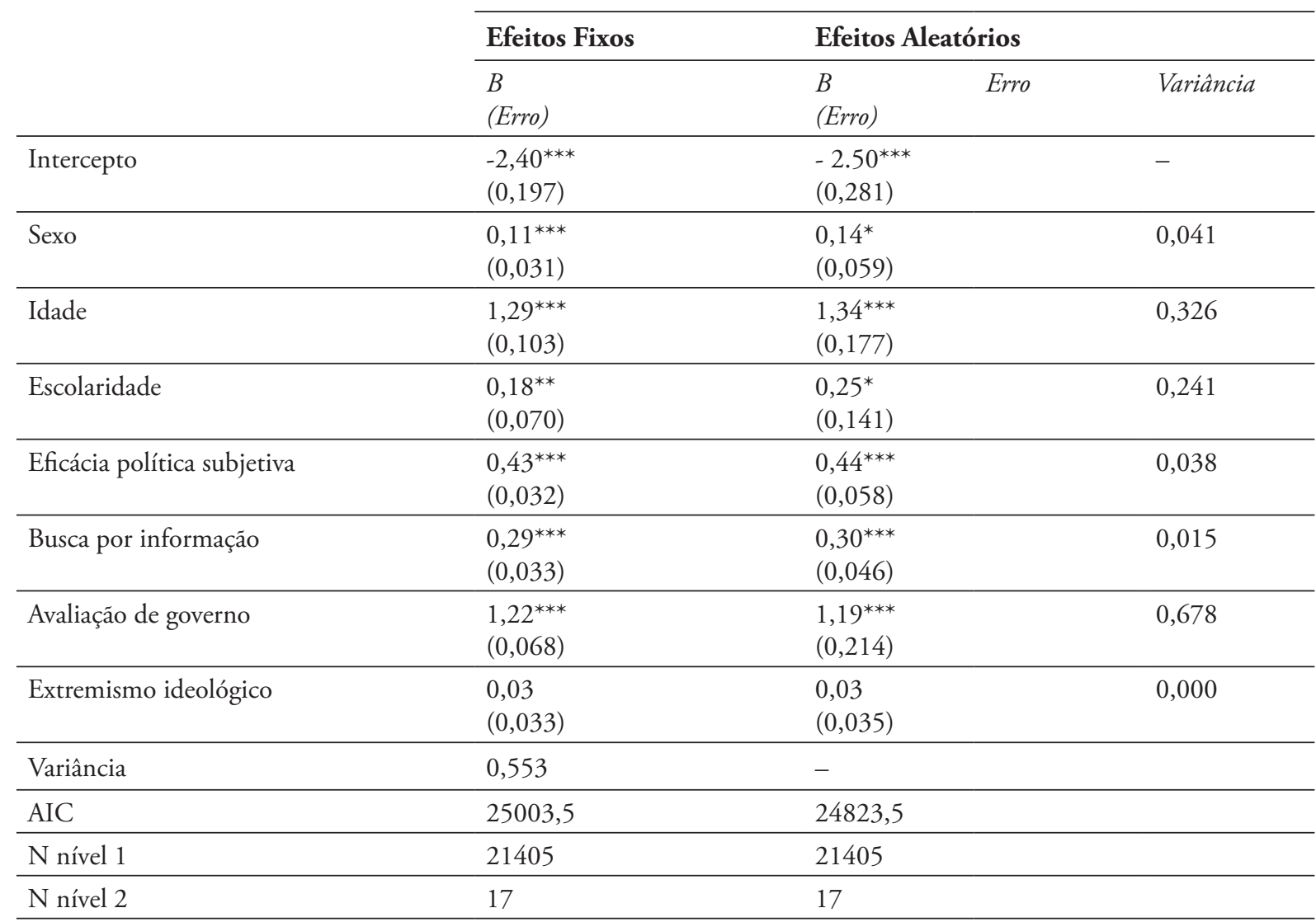

Notas: $\operatorname{sig}^{* * *}=0,001 ;^{* *}=0,01 ;^{*}=0,05$.

Fonte: Lapop (2014).

nível individual. Percebemos elevações sutis nos efeitos das variáveis individuais na presença dos preditores nacionais, sendo novamente exceção a avaliação de governo, que registra redução no efeito, ainda que levemente.

Entre as variáveis nacionais, duas se mostraram preditores estatisticamente significativos. A primeira delas foi o indicador econômico, com efeito positivo sobre a probabilidade de manifestar identificação partidária. O coeficiente de 0,011 (exponencial de 1,01) indica que a cada ponto na escala de 100 pontos eleva em $1 \%$ a probabilidade de identificação dos eleitores. A idade da democracia também se mostrou relevante e com efeito maior. O coeficiente estimado foi de 0,032 (expo- nencial de 1,03), indicando a cada ponto da escala de durabilidade do sistema um incremento de 3\% na probabilidade de identificação. Em síntese, cidadãos de países com maior renda per capita e com democracias mais longevas tendem a apresentar probabilidade maior de identificação com alguma legenda partidária. Ainda que esses valores pareçam pequenos, é preciso lembrar que as escalas padronizadas de ambas as variáveis são amplas (0-100), o que garante efeitos cumulativos bastante expressivos, já que existe grande variabilidade entre os países. Considerando a medida econômica, temos países com pontuaçóes abaixo de 10 e outros com pontuação entre 40 e 50 . Na medida sobre democracia, enquanto registramos países com pontua- 
çóes na casa dos 30, outros atingem mais de 80 . Essas diferenças tornam os efeitos dessas duas medidas expressivos.

Por fim, considerando esse efeito da durabilidade da democracia, especificamos um modelo com algumas interaçóes entre essa medida de nível nacional e os preditores de nível individual que apresentam variaçóes expressivas em seus efeitos entre os países, conforme Tabela 4 (coluna "Efeitos Aleatórios"). Essas interaçóes foram produzidas pela multiplicação da escala de idade do regime com as medidas de idade, escolaridade e avaliação de governo. Nossa intenção com esse procedimento era verificar se de alguma forma essa dimensão política pode afetar a forma como essas variáveis individuais impactam a identificação partidária.

Os resultados da Tabela 5 (segunda coluna) indicam que apenas a interação com a idade dos entrevistados atingiu nível de significância estatística mínimo. Nesse caso, o coeficiente negativo indica que em contextos com maior longevidade das instituições democráticas o efeito dessa medida tende a ser menor, fazendo com que a diferença entre mais velhos e mais jovens seja reduzida.

\section{Consideraçóes finais}

Os resultados do estudo denotam a exploração analítica das relações entre as instituições políticas, as atitudes e o comportamento político na América Latina. O objeto empírico, a simpatia partidária, permitiu que verificássemos que essa dimensão das atitudes políticas é permeada pela relação entre a centralidade do indivíduo na estrutura social (Reis, 2000), a dimensão propriamente avaliativa (mensurada em nosso estudo pela avaliação de governo) e a configuração histórica das instituições políticas (medida pela idade da democracia). Os aspectos relacionados a centralidade social, analisados no âmbito individual, corroboram os resultados de várias pesquisas produzidas em diferentes contextos: homens, pessoas mais velhas, de maior nível educacional, com maior sentimento de eficácia política subjetiva e maior disposição em adquirir informação têm maior probabilidade de desenvolver identificação com partidos. Outras duas variáveis indivi- duais se mostraram relevantes: a avaliação positiva de governos e o extremismo ideológico também aumentam a probabilidade de um eleitor se identificar partidariamente. No primeiro caso, nossa hipótese explicativa é a de que, em momentos em que o governo está mal avaliado, a simpatia pelo(s) partido(s) do governo deve declinar e, se nenhum partido de oposiçáo se beneficiar disso, a simpatia partidária como um todo tende a diminuir. No caso do extremismo ideológico, a hipótese é a de que o vínculo entre eleitores ideologicamente mais extremistas com os partidos que são próximos a eles seria mais forte do que com os eleitores centristas.

Por outro lado, quando passamos para a dimensão do contexto, em trabalho anterior (Borba, Gimenes e Ribeiro, 2015) foi apontada uma chave analítica para a explicação do fenômeno através da relação entre instituição e cognição, quando verificamos que sistemas partidários mais fragmentados produziam menos IP. Agora, quando inserimos outras variáveis de contexto, essa e outras dimensôes estruturais do sistema político deixam de surtir efeito, com exceção da idade da democracia, o que nos permite sugerir que os aspectos relacionados ao aprendizado político (ou "decantação") ganham relevância explicativa, confirmando nossa hipótese inicial de que, no contexto das novas democracias, o tempo de convivência democrática é mais importante que as diversas configuraçóes internas que esta pode assumir.

Nesse sentido, tal resultado confirma, para as novas democracias latino-americanas, o argumento teórico desenvolvido por Converse (1969) para democracias consolidadas, de que a persistência da democracia seria mais relevante ao enraizamento dos partidos políticos na sociedade do que características formais da "engenharia" do arranjo político-partidário, nos termos de Reis (2003).

Em suma, nosso estudo indica que, para a explicação sobre a simpatia partidária em contextos de novas democracias, como as latino-americanas, o tempo de persistência do regime é mais importante do que as diversas configuraçóes internas que estes podem assumir. Em outras palavras, a formação de identidades partidárias, embora com diferentes probabilidades de ocorrer, dependendo do grau de centralidade da posição do indivíduo 
Tabela 5

Preditores de Nível Individual e Nacional para Identificaçáo Partidária (América Latina, 2014)

\begin{tabular}{|c|c|c|}
\hline & \\
\hline & Sem interaçóes & Com interaçóes \\
\hline & B(Erro) & B(Erro) \\
\hline Intercepto & $\begin{array}{l}-4,42^{* * *} \\
(0,472)\end{array}$ & $\begin{array}{l}-4,72^{* * *} \\
(0,516)\end{array}$ \\
\hline Sexo & $\begin{array}{l}0,14^{*} \\
(0,059)\end{array}$ & $\begin{array}{l}0,13^{*} \\
(0,058)\end{array}$ \\
\hline Idade & $\begin{array}{l}1,29^{* * *} \\
(0,187) \\
\end{array}$ & $\begin{array}{l}2,30^{* * *} \\
(0,491)\end{array}$ \\
\hline Escolaridade & $\begin{array}{l}0,23^{*} \\
(0,144)\end{array}$ & $\begin{array}{l}-0,141 \\
(0,415)\end{array}$ \\
\hline Eficácia política subjetiva & $\begin{array}{l}0,44^{* * *} \\
(0,057)\end{array}$ & $\begin{array}{l}0,44^{* * *} \\
(0,057)\end{array}$ \\
\hline Busca por informação & $\begin{array}{l}0,30^{* * *} \\
(0,048)\end{array}$ & $\begin{array}{l}0,30^{* * *} \\
(0,048)\end{array}$ \\
\hline Avaliação de governo & $\begin{array}{l}1,167^{* * *} \\
(0,215) \\
\end{array}$ & $\begin{array}{l}1,872^{* *} \\
(0,632) \\
\end{array}$ \\
\hline Extremismo ideológico & $\begin{array}{l}0,031 \\
(0,034)\end{array}$ & $\begin{array}{l}0,031 \\
(0,034)\end{array}$ \\
\hline PIB & $\begin{array}{l}0,011^{*} \\
(0,004)\end{array}$ & $\begin{array}{l}0,011^{* *} \\
(0,004)\end{array}$ \\
\hline NEP & $\begin{array}{l}0,001 \\
(0,005) \\
\end{array}$ & $\begin{array}{l}0,001 \\
(0,005) \\
\end{array}$ \\
\hline Sistema eleitoral & $\begin{array}{c}-0,197 \\
(0,226) \\
\end{array}$ & $\begin{array}{c}-0,197^{*} \\
(0,226) \\
\end{array}$ \\
\hline Idade da democracia & $\begin{array}{l}0,032^{* * *} \\
(0,006) \\
\end{array}$ & $\begin{array}{l}0,038^{* * *} \\
(0,007) \\
\end{array}$ \\
\hline Idade & - & $\begin{array}{l}-0,019^{*} \\
(0,009)\end{array}$ \\
\hline Escolaridade & - & $\begin{array}{l}0,007 \\
(0,007) \\
\end{array}$ \\
\hline Avaliação de governo & - & $\begin{array}{l}-0,013 \\
(0,011) \\
\end{array}$ \\
\hline AIC & 24813,15 & 24812 \\
\hline $\mathrm{N}$ nível 1 & 21405 & 21405 \\
\hline N nível 2 & 17 & 17 \\
\hline
\end{tabular}

Notas: $\operatorname{sig}^{* * *}=0,001 ;^{* *}=0,01 ;^{*}=0,05$.

Fonte: Lapop (2014); Databank/World Bank (2013); Center of Systemic Peace (2013); Pérez-Liñán; Mainwaring (2013); Nicolau, 2012; Power (2015). 
na sociedade, seria, em boa medida, também produto de processos de "decantação", de acúmulo de experiência eleitoral pelas geraçóes, especialmente de aprendizado a respeito do que representam os principais partidos políticos, aumentando a chance de que os eleitores se identifiquem com algum deles. Mesmo dificuldades provocadas por uma maior fragmentação do sistema partidário - aspecto central no caso brasileiro - parecem ser minimizados com o aprendizado possibilitado pela convivência contínua com as instituições democráticas.

\section{Notas}

1 O conceito de centralidade social faz referência à posição do indivíduo na estrutura social, em termos de sua aproximação ao "centro" da sociedade, tomando como referência um conjunto de dimensóes objetivas e subjetivas (Reis, 2000).

2 Retomamos aqui, de forma resumida, a revisão realizada em Gimenes (2015).

3 Assumimos a medida de identificação partidária como proxy de partidarismo, assim como em Gimenes (2015, p. 21), quando afirmamos que tal indicador permite "representar empiricamente o conceito de partidarismo, o que, apesar de aparentemente simples, pode conduzir a equívocos reducionistas, como a sua restrição à filiação a legendas. Defendemos aqui que esse conceito se refere a algo mais amplo, pois designa um padrão de relacionamento entre cidadáos e essas instituiçóes centrais do sistema democrático. Nestes termos, é importante o comportamento efetivo de participação formalizada ou não, mas também devem ser levadas em consideração dimensóes atitudinais e valorativas, como a simpatia partidária e a identificação com uma legenda”.

4 Em que pese tal suposição enfrentar vários questionamentos na literatura recente sobre comportamento eleitoral. Para um balanço da literatura, ver Rennó (2001).

5 A socialização primária, nos termos de Dahl (1997).

6 Tomando a América Latina como objeto analítico, nos debruçamos especificamente sobre resultados que contribuam à construção do conhecimento sobre o partidarismo na região. Contudo, ainda que não tenhamos exposto discussóes de âmbito local, não desconsideramos a produção sobre unidades nacionais, como, por exemplo: sobre a relação entre "partidos sem políti- cos" e "políticos sem partidos" no Peru (Taylor, 2007); sobre as oscilaçóes do Partido Acción Nacional (PAN) no poder e junto à sociedade (Hernández, 2011) e ao retorno do Partido Revolucionário Institucional (PRI) à presidência no fim da década passada no México (Olmeda e Armesto, 2013); sobre as mudanças no sistema partidário e a contestação do argumento da força do partidarismo no Chile (Ortega Frei, 2003), as crises e revoltas populares relacionadas ao Partido Comunista naquele país (Valdebenito, 2009) e o descontentamento da população, especialmente jovem, com os partidos políticos nacionais (Bargsted e Maldonado, 2013); sobre a relação entre partidos políticos e sociedade civil e as discussóes em torno da participação nos espaços públicos na Venezuela (Dávila e Jiménez, 2004); sobre a relação entre estabilidade e renovação nas eleiçóes colombianas (Daza, 2011) e suas implicaçóes à nacionalização do sistema partidário nacional no fim da última década (Batlle e Puyana, 2011); a tradição de partidos locais (Blanco Lizano, 2002) e a ausência de sançóes à abstenção eleitoral na Costa Rica (Fernández e Thompson, 2007); a novidade das eleições municipais no Uruguai a partir de 2010 (Došek, 2016), o comparecimento eleitoral diante da imposição de sanções (Fernández e Thompson, 2007) e do controle exercido pelos partidos tradicionais (Došek, 2016); e os estudos sobre formação (Lamounier e Cardoso, 1978; Reis, 1978; Lamounier, 1980; Lavareda, 1991) e significados da identificação partidária no Brasil (Figueiredo, 1991; Castro, 1992; Meneguello, 1995; Carreirão e Kinzo, 2004; Pimentel Junior, 2007; Ribeiro, Carreirão e Borba, 2011), bem como sua relação com o comparecimento eleitoral dos brasileiros (Meneguello, 1995; Silveira, 1998; Reis, 2000; Carreirão e Kinzo, 2004; Baker, Ames e Rennó, 2006; Pimentel Junior, 2007; Nicolau, 2007; Braga e Pimentel Junior, 2011; Paiva e Tarouco; 2011; Samuels e Zucco Junior, 2014a; 2014b; 2015; Pereira; 2014; Bakeret al., 2015; Speck, Braga e Costa; 2015; Speck e Balbachevsky, 2016).

7 Um balanço das obras destacadas neste parágrafo é oferecido por Gimenes (2015).

8 A questão do Lapop era: "Atualmente o/a sr./sra. simpatiza com algum partido político?". O uso de simpatia partidária como proxy de identificação partidária está devidamente justificado na nota 3 .

9 Informações técnicas sobre as variáveis encontram-se nos apêndices metodológicos.

10 A questão do Lapop era: "O/A Sr./sra. sente que entende bem os assuntos políticos mais importantes do país. Até que ponto concorda ou discorda dessa fra- 
se?". Recodificamos a escala original de 7 pontos para: $1 \mathrm{a} 4$ = baixa; 5 a 7 = alta.

11 A variável do Lapop apresenta escala de cinco pontos, com variação de "muito ruim" até "muito boa".

12 Esse tipo de situação ocorreu com o Brasil nos últimos anos do governo Dilma Rousseff, que sofreu uma queda brutal em sua avaliação (devido a denúncias de corrupção, baixo desempenho econômico, não cumprimento de promessas de campanha), o que gerou declínio substancial da simpatia pelo PT - há quase vinte anos o partido que desfruta da maior taxa de identificação partidária no país -, sem que nenhum partido de oposição se beneficie com um aumento na taxa de simpatia partidária. Fenômeno semelhante também ocorreu ao longo do segundo semestre de 2005, quando estourou o escândalo de corrupçáo do "mensalão", envolvendo figuras importantes do PT e do governo.

13 Segundo Lupu (2014), o comportamento das elites estaria na base da explicação para esse declínio. Especialmente em períodos de crises econômicas, como as que ocorreram na América Latina nos anos de 1980 e 1990, alguns líderes partidários acabaram por adotar políticas (e alianças) inconsistentes com o ideário de seus partidos, visando resultados no curto prazo, o que fez com que perdessem boa parte de sua base de apoio. Em momentos de baixo desempenho desses partidos, quando exercendo o governo, eles não contam mais com aquela base, ficando sujeitos a um rápido declínio.

14 A criação de novos partidos tem sido estimulada especialmente após a definição, em 2007, pelo Tribunal Superior Eleitoral (TSE), da possibilidade de perda de mandato por parte de parlamentares que migrarem para outros partidos já existentes, já que a migração para novos partidos não acarreta a perda de mandato.

$15 \mathrm{O}$ modelo foi estimado com o uso do pacote lmé, desenvolvido para o ambiente R por Douglas Bates e Martin Maechler para ajustar modelos de efeitos mistos lineares e lineares generalizados.

16 As informaçôes mais relevantes desse modelo são apresentadas no Apêndice Metodológico.

17 Para facilitar a interpretaçấo dos resultados foram calculados os exponenciais de $\mathrm{B}$.

18 Chegamos a essa representação percentual dos efeitos com o procedimento $(\operatorname{Exp}(B)-1)^{*} 100$.

\section{BIBLIOGRAFIA}

ALBALA, A. \& VIEIRA, S. M. (2014), “ ¿Crisis de los partidos en América Latina? El papel de los partidos políticos latinoamericanos en el escenario reciente". Politica - Revista de Ciência Politica, 52 (1): 145-170.

ALCÁNTARA SÁEZ, M. \& FREIDENBERG, F. (2002), "Partidos políticos na América Latina". Opinião Pública, 8 (2): 137-157.

ALMOND, G. A. \& VERBA, S. ([1963] 1989), The civic culture: political attitudes and democracy in five nations. 3. ed. Nova York, Sage.

BAKER, A.; AMES, B. \& RENNÓ, L. (2006), "Social context and campaign volatility in new democracies: networks and neighborhoods in Brazil's 2002 elections". American Journal of Political Science, 50 (2): 379-396.

BAKER, A.; SOKHEY, A. E.; AMES, B. \& RENNÓ, L. R. (2015), The dynamics of party identification when party brands change: the case of the Workers Party in Brazil [mimeo.].

BAQUERO, M. (2000), A vulnerabilidade dos partidos politicos e a crise da democracia na América Latina. Porto Alegre, Editora UFRGS.

BARGSTED, M. \& MALDONADO, L. (2013), Social change and political identification in contemporary Chile. Working paper. Disponível em www. imd.cl/uc/images/stories/investigacion/apc_party_id_chile.pdf, consultado em 25/1/2015.

BATLLE, M. \& PUYANA, J. R. (2011), “El nivel de nacionalización del sistema de partidos colombiano: una mirada a partir de las elecciones legislativas de 2010". Colombia Internacional, 74: 27-57.

BLANCO LIZANO, R. (2002), "Los partidos cantonales en las elecciones municipales de Costa Rica: 1949-2002. Una interpretación sociológica". Anuario de Estudios Sociales Centroamericanos, 28 (1-2): 161-186.

BORBA, J; GIMENES, E. R.; RIBEIRO, E. A. (2015), "Os determinantes do ativismo partidário na América Latina”. Revista Latinoamericana de Opinión Pública, 5: 13- 47.

BRAGA, M. do S. S. \& PIMENTEL JUNIOR, J. (2011), "Os partidos políticos brasileiros realmente não importam?”. Opinião Pública, 17 (2): 271-303. 
BURNHAM，K. P. \& ANDERSON, D. R. (2002), Model selection and multimodel inference: a practical information-theoretic approach. 2. ed. Nova York, Springer.

CAMPBELL, A.; CONVERSE, P. E.; MILLER, W. E. \& STOKES, D. E. (1960), The American voter. Nova York, Wiley.

CAREY, J. \& SUGAR, M. (1995), "Incentives to cultivate a personal vote: a rank ordering of electoral formulas". Electoral Studies, 14 (4): 417-439.

CARREIRÁO, Y. de S. (2014), "O sistema partidário brasileiro: um debate com a literatura recente". Revista Brasileira de Ciência Politica, 14: 255-295.

CARREIRÃO, Y. de S. \& KINZO, M. D. (2004), "Partidos políticos, preferência partidária e decisão eleitoral no Brasil (1989-2002)". Dados, 47 (1): 131-168.

CARRERAS, M.; MORGENSTERN, S. \& SU, Y. -P. (2013), "Refining the theory of partisan alignments: evidence from Latin America". Party Politics: 1-15.

CASTRO, M. M. M. (1992), "Sujeito e estrutura no comportamento eleitoral". Revista Brasileira de Ciências Sociais, 20: 7-19.

CLARKE, H. D. \& STEWART, M. C. (1998), "The decline of parties in the minds of citizens". Annual Reviews Political Science, 1: 357378.

CONVERSE, P. (1969), "Of time and partisan stability”. Comparative Political Studies, 2: 139171.

DAHL, R. A. (1997), Poliarquia: participação e oposição. São Paulo, Edusp.

DALTON, R. J. (2013), Theapartisan American: dealignment and changing electoral politics. Washington, Sage.

DALTON, R. J.; McALLISTER, I. \& WATTENBERG, M. (2003), "Democracia e identificação partidária nas sociedades industriais avançadas". Revista Análise Social, 38 (167): 295-320.

DALTON, R. J. \& WATTENBERG, M. (2002), Parties without partisans: political change in advanced industrial democracies. Oxford: Oxford University Press.
DALTON, R. \& WELDON, S. (2007), "Partisanship and party system institutionalization". Party Politics, 12 (2): 179-196.

DÁVILA, S. C. \& JIMÉNEZ, J. E. R. (2004), "Consideraciones sobre la sociedad civil y los partidos políticos en Venezuela dentro de la problemática de las democracias en América Latina”. Historia Actual Online, 3: 7-15.

DAZA, J. D. (2011). "Redefinición de las reglas de juego. Las reformas al sistema electoral colombiano como un caso de volatilidad institucional, 1991-2011”. Papel politico, 16 (2): 421-460.

DOŠEK, T. (2016), "Los caminos divergentes a nivel subnacional de los sistemas de partidos más institucionalizados: Chile, Costa Rica y Uruguay en perspectiva comparada", in F. Tuesta Soldevilla (org.), Partidos políticos y elecciones: representación politica en América Latina, Lima, Jurado Nacional de Elecciones/Pontifícia Universidad del Peru.

DOWNS, A. (1957), An economic theory of democracy. Nova York, Harper Row.

FERNÁNDEZ, M. \& THOMPSON, J. (2007), "El voto obligatorio", in D. Nohlen, D. Zovatto, J. O. Henríquez e J. Thompson (orgs.), Tratado de derecho electoral comparado de América Latina, Cidade do México, Universidad de Heidelberg/IDEA Internacional/Tribunal Electoral del Poder Judicial de la Federación/ IFE/Fondo de Cultura Económica.

FIGUEIREDO, M. (1991). A decisão do voto. São Paulo, Idesp/Sumaré.

FIORINA, M. (1981), Retrospective voting in American national elections. New Haven (CT), Yale University.

FONSECA, F. (2013), "Mídia e eleição na transição democrática brasileira: aspectos conceituais e empíricos da vitória eleitoral do presidente Collor de Mello", in H. Telles e A. Moreno (orgs.), Comportamento eleitoral e comunicação politica na América Latina: o eleitor latino-americano. Belo Horizonte, Editora UFMG.

FREIRE, A. (2005), "Identidades ideológicas e partidárias na Europa: Portugal, Espanha e Grécia em perspectiva comparada”. Revista Sociologia, Problemas e Práticas, 47: 11-33. 
GARRETÓN, M. A. (1993), "Transformaciones socio-políticas en América Latina, 1972-1992”, in M. A. Garretón (org.), Los partidos y la transformación politica de América Latina, Córdoba, Facultad Latinoamericana de Ciencias Sociales.

GIMENES, E. R. (2015), A relação dos eleitores com partidos politicos em novas democracias: partidarismo na América Latina. Tese de doutorado, Florianópolis, UFSC.

GREEN, D.; PALMQUIST, B. \& SCHICKLER, E. (2002), Partisan hearts \& minds: political parties and the social identities of voters. New Haven (CT), Yale University.

HEIDAR, K. (2006), "Party membership and participation”, in Richard S. Katz e William Crotty, Handbook of party politics, Londres, Sage.

HERNÁNDEZ, T. (2011), "El Partido Acción Nacional y la democracia cristiana”. Revista Perfiles Latinoamericanos, 19 (37): 113-138.

HUNTINGTON, S. (1994), A terceira onda: a democratização no final do século XX. São Paulo, Ática.

INGLEHART, R. \& WELZEL, C. (2009), Modernização, mudança cultural e democracia: a sequência do desenvolvimento humano. São Paulo, Francis.

KLEIN, C. (2007), O desafio da reforma politica: consequências dos sistemas eleitorais de listas aberta e fechada. Rio de Janeiro, Mauad.

LAAKSO, M. \& TAAGEPERA, R. (1979), "Effective number of parties: a measure with application to West Europe". Comparative Political Studies, 12 (1): 3-27.

LAMOUNIER, B. (org.). (1980), Voto de desconfiança: eleiçóes e mudança política no Brasil, 1970-1979. Petrópolis (RJ), Vozes.

LAMOUNIER, B. \& CARDOSO, F. H. (orgs.). (1978), Os partidos e as eleiçóes no Brasil. 2. ed. Rio de Janeiro/São Paulo: Paz e Terra/Cebrap.

LAVAREDA, A. (1991), A democracia nas urnas: o processo partidário-eleitoral brasileiro. Rio de Janeiro: Rio Fundo Editora/Iuperj.

LISI, M. (2014), “The sources of mass partisanship in newer democracies: Social identities or performance evaluations? Southern Europe in comparative perspective". International Political Science Review, 35 (5): 505-522.
LUPU, N. (2014), Party brands in crisis: partisanship, brand dilution, and the breakdown of political parties in Latin America. Disponível em www.noamlupu.com/Brands_in_Crisis _Ch1.pdf, consultado em 21/7/2015.

LUPU, N. (2015), "Partisanship in Latin America”, in R. E. Carlin, M. M. Singer, E. J. Zechmeister (orgs.), The Latin American voter: pursuing representation and accountability in challenging contexts, Ann Arbor, Michigan University Press. Disponível em www. noamlupu. com/partisanshipLAV.pdf>, consultado em 23 jan. 2015.

MAINWARING, S. (2001), Sistemas partidários em novas democracias: o caso do Brasil. Porto Alegre/Rio de Janeiro, Mercado Aberto/Editora FGV.

MAINWARING, S. P. \& TORCAL, M. (2005), "Teoria e institucionalização dos sistemas partidários após a terceira onda de democratização”. Opinião Pública, 11 (2): 249-286.

MAINWARING, S. \& ZOCO, E. (2007), "Political sequences and the stabilization of interparty competition”. Party Politics, 12 (2): 155-178.

MAIR, P. (2003), "Os partidos políticos e a democracia”. Revista Análise Social, 38 (167): 277-293.

MAIR, P. \& VAN BIEZEN, I. (2001), "Party membership in twenty European democracies". Party Politics, 7 (1): 5-21.

MCCULLAGH, P. \& NELDER, J. A. (1989), Generalized linear models. 2. ed. Nova York, Chapman \& Hall.

MENEGUELLO, R. (1995), "Electoral behavior in Brazil: the 1994 presidential election". International Social Science Journal, 146: 627-642.

MILLER, W. \& SHANKS, J. M. (1996), The new American voter. Cambridge (MA), Harvard University Press.

MORALES, L. (2005), “¿Existe una crisis participativa? La evolución de la participación política y el asociacionismo en España”. Revista Española de Ciencia Política, 13: 51-87.

MORENO, A. (2015), "Partidarismo e ideologia nos eleitorados latino-americanos", in $\mathrm{H}$. Telles e A. Lavareda (orgs.), Voto e estratégia de comunicação política na América Latina, Curitiba, Appris. 
NICOLAU, J. (2007), "An analysis of the 2002 presidential elections using logistic regression". Brazilian Political Science Review, 1 (1): 125-135.

NICOLAU, J. (2012), Sistemas eleitorais. 6. ed. Rio de Janeiro, Editora FGV.

NORRIS, P. (1999), Critical citizens: global support for democratic governance. Oxford, Oxford University Press.

NORRIS, P. (2002), "Electoral reform and fragmented multipartyism: the mechanical and psychological effects of electoral systems on party systems". Reforma politica no Brasil em perspectiva comparada [conferência internacional]. Rio de Janeiro, Universidade Cândido Mendes.

NORRIS, P. (2011), Democratic deficit: critical citizens revisited. Nova York, Cambridge University Press.

OLMEDA, J. C. \& ARMESTO, M. A. (2013), "México: el regreso del PRI a la presidencia". Revista de Ciencia Politica, 33 (1): 247-267.

ORTEGA FREI, E. (2003). "Los partidos políticos chilenos: cambio y estabilidad en el comportamiento electoral 1990-2000". Revista de Ciencia Política, 23 (2): 109-147.

PAIVA, D. \& TAROUCO, G. S. (2011), "Voto e identificação partidária: os partidos brasileiros e a preferência dos eleitores". Opinião Pública, 17 (2): 426-451.

PAYNE, J. M. (2007), "Party systems and democratic governability" in J. M. Payne et al., Democracies in development: politics and reform in Latin America, Washington, Inter-American Development Bank/International Institute for Democracy and Electoral Assistance/David Rockefeller Center for Latin American Studies/Harvard University Press.

PEREIRA, F. B. (2014), "A estabilidade e a efetividade da preferência partidária no Brasil". Revista Brasileira de Ciência Política, 13: 213-244.

PÉREZ-LIÑÁN, A. \& MAINWARING, S. (2013), "Regime legacies and levels of democracy: evidence from Latin America". Comparative Politics, 45 (4): 379-397.

PIMENTEL JUNIOR, J. (2007), "Disposiçóes afetivas e laços partidários", in M. D. G. Kinzo e M. do S. S. Braga (orgs.), Eleitores e representação partidária no Brasil, São Paulo, Humanitas.
POWER, T. J. (2015), "Presidencialismo de coalizão e o design institucional no Brasil: o que sabemos até agora?", in A. Sathler e R. Braga (orgs.), Legislativo pós-1988: reflexóes e perspectivas, Brasília, Câmara dos Deputados.

PUTNAM, R. D. (org.). (2003), El declive del capital social. Barcelona, Galaxia Gutenberg.

RAUDENBUSH, S. W. \& BRYK, A. S. (2002), Hierarchical linear models: applications and data analysis methods. Nova York, Sage.

REIS, F. W. (1978), Os partidos e o regime: a lógica do processo eleitoral brasileiro. São Paulo, Símbolo.

REIS, F. W. (2000), Mercado e utopia: teoria politica e sociedade brasileira. São Paulo, Edusp.

REIS, F. W. (2003), "Engenharia e decantação", in M. V. Benevides, P. Vanucchi e F. Kerche (orgs.), Reforma política e cidadania, São Paulo, Fundação Perseu Abramo.

RENNÓ, L. R. (2001), "A estrutura das crenças de massa e seu impacto na decisão de voto". BIBRevista Brasileira de Informação Bibliográfica em Ciências Sociais, 51: 85-102.

RIBEIRO, E. A.; CARREIRÃO, Y. de S. \& BORBA, J. (2011), "Sentimentos partidários e atitudes políticas entre os brasileiros". Opinião Pública, 17 (2): 333-368.

RICO, G. (2010), "La formación de identidades partidistas en Europa: más allá de la teoría de Converse", in M. Torcal (org.), La ciudadania europea en el siglo XXI, Madri, Centro de Investigaciones Sociológicas.

SAMUELS, D. (1997), "Determinantes do voto partidário em sistemas eleitorais centrados no candidato: evidências sobre o Brasil". Dados, 42 (3): 493-535.

SAMUELS, D. \& ZUCCO, C. (2014a), "Lulismo, petismo and the future of Brazilian politics". Journal of Politics in Latin America, 6 (3): 129-158.

SAMUELS, D. \& ZUCCO, C. (2014b), "The power of partisanship in Brazil: evidence from survey experiments". American Journal of Political Science, 58 (1): 212-225.

SAMUELS, D. \& ZUCCO, C. (2015), "Partisans, anti-partisans and voting behavior in Brazil". 111th APSA Annual Meeting \& Exhibition. São Francisco (CA), 2-6 set. 
SCARROW, S. E. \& GEZGOR, B. (2010), "Declining memberships, changing members? European political party members in a new era". Party Politics, 16 (6): 823-843.

SEYD, P. \& WHITELEY, P. (2004), "British party members: an overview”. Party Politics, 10 (4): 355-366.

SILVEIRA, F. (1998), A decisão de voto no Brasil. Porto Alegre, Edipucrs.

SNIJDERS, T. A. \& BOSKER, R. J. (1999), Multilevel analysis: an introduction to basic and advanced multilevel modeling. Londres, Sage.

SPECK, B. \& BALBACHEVSKY, E. (2016), "Identificação partidária e voto: as diferenças entre petistas e peessedebistas". Opinião Pública, 22 (3): 569-602.

SPECK, B.; Braga, M. S. de S.; Costa, V. (2015), "Estudo exploratório sobre filiação e identificação partidária no Brasil". Revista de Sociologia e Politica, 23 (56): 125-148.

TAYLOR, L. (2007), "Politicians without parties and parties without politicians: the foibles of the Peruvian political class, 2000-2006". Bulletin of Latin American Research, 26 (1): 1-23.

VALDEBENITO, H. V. (2009), "Trayectoria del Partido Comunista de Chile: de la crisis de la unidad popular a la política de rebelión popular de masas". Universum, 24 (2): 262-293.

VAN BIEZEN, I.; MAIR, P. \& POGUNTKE, T. (2012), "Going, going, ... gone? The decline of party membership in contemporary Europe". European Journal of Political Research, 51: 24-56.

VERBA, S.; SCHLOZMAN, K. L. \& BRADY, H. E. (1995), Voice and equality: civic voluntarism in American politics. Cambridge (MA), Harvard University Press.

WEISBERG, H. F. \& GREENE, S. (2003), “The political psychology of party identification”, in M. B. Mackuen e G. Rabinowitz (orgs.), Electoral democracy. Ann Arbor, University of Michigan Press.

WITHELEY, P. F. (2011), "Is the party over? The decline of party activism and membership across the democratic world". Party Politics, 17: 21-44.

WITHELEY, P. F. \& SEYD, P. (1998), "The dynamics of party activism in Britain: a spiral of desmobilization?". British Journal of Political Science, 28 (1): 113-137.
WITHELEY, P. F. \& SEYD, P. (2002), High intensity participation: the dynamics of party activism in Britain. Ann Arbor, University of Michigan Press. 


\section{Apêndice metodológico}

Tabela A

Correlaçôes entre Características Nacionais (América Latina, 2013)

\begin{tabular}{lllll}
\hline País & Crescimento do PIB & Fragmentaçáo & $\begin{array}{l}\text { Idade da } \\
\text { democracia }\end{array}$ & $\begin{array}{l}\text { Sistema } \\
\text { eleitoral }\end{array}$ \\
\hline Crescimento do PIB & 1 & $-0,249$ & $-0,260$ & $-0,035$ \\
\hline Fragmentaçáo & & 1 & 0,076 & $-0,243$ \\
\hline Idade da democracia & & 1 & 0,290 \\
\hline Sistema eleitoral & & & 1 \\
\hline
\end{tabular}

Notas/Fontes: Crescimento do PIB per capita registrado em 2013 (Databank/World Bank); Polity IV de 2013 (Center of Systemic Peace); idade da democracia (em anos) até 2013 (Pérez-Liñán; Mainwaring, 2013); sistema eleitoral vigente em 2013, com 0 = proporcional/lista aberta e 1 = lista fechada/maioria simples/misto (Nicolau, 2012; Political Database of the Americas); fragmentação (Power, 2015).

Tabela B

Correlaçôes entre Características Individuais (América Latina, 2014)

\begin{tabular}{|c|c|c|c|c|c|c|c|}
\hline País & Sexo & Idade & Escolaridade & Eficácia & Informaçáo & Avaliaçáo & Extremismo \\
\hline Sexo & 1 & 0,010 & 0,044 & $0,169^{*}$ & $0,077^{*}$ & $-0,006$ & $-0,044$ \\
\hline Idade & & 1 & $-0,089^{*}$ & 0,029 & $0,065^{*}$ & $0,103^{*}$ & $0,101^{*}$ \\
\hline Escolaridade & & & 1 & $0,169^{*}$ & $0,167^{*}$ & $-0,113^{*}$ & $-0,072^{*}$ \\
\hline Eficácia & & & & 1 & $0,181^{*}$ & $-0,025$ & 0,017 \\
\hline Informação & & & & & 1 & $-0,015$ & $0,081^{*}$ \\
\hline Avaliação & & & & & & 1 & 0,020 \\
\hline Extremismo & & & & & & & 1 \\
\hline
\end{tabular}

Notas: ${ }^{*}$ sig. $<0,05$.

Fonte: Elaborada pelos autores com dados de Lapop (2014). 
Quadro A

Incentivo ao Voto Partidário Segundo os Sistemas Eleitorais

\begin{tabular}{lll}
\hline País & Sistema eleitoral & Valor \\
\hline Argentina & PROPORCIONAL - LISTA FECHADA & 1 \\
\hline Bolívia & MISTO (70 cadeiras: maioria simples; 53 cadeiras: lista fechada) & 1 \\
\hline Brasil & PROPORCIONAL - LISTA ABERTA & 0 \\
\hline Chile & PROPORCIONAL - LISTA ABERTA & 0 \\
\hline Colômbia & PROPORCIONAL - LISTA FECHADA & 1 \\
\hline Costa Rica & PROPORCIONAL - LISTA FECHADA & 1 \\
\hline Equador & PROPORCIONAL - LISTA ABERTA & 0 \\
\hline El Salvador & PROPORCIONAL - LISTA FECHADA & 1 \\
\hline Guatemala & PROPORCIONAL - LISTA FECHADA & 1 \\
\hline Honduras & PROPORCIONAL - LISTA ABERTA & 0 \\
\hline México & MISTO (300 cadeiras: maioria simples; 200 cadeiras: lista fechada) & 1 \\
\hline Nicarágua & PROPORCIONAL - LISTA FECHADA & 1 \\
\hline Panamá & PROPORCIONAL - LISTA ABERTA & 0 \\
\hline Paraguai & PROPORCIONAL - LISTA FECHADA & 1 \\
\hline Peru & PROPORCIONAL - LISTA ABERTA & 0 \\
\hline Uruguai & PROPORCIONAL - LISTA FECHADA & 1 \\
\hline Venezuela & MISTO (110 cadeiras: maioria simples; 52 cadeiras: lista fechada) & 1 \\
\hline
\end{tabular}

Nota: *Bolívia: mais sete representantes da população indígena, eleitos via "usos e costumes".

Fontes: Nicolau (2012); Political Database of the Americas [online]. 


\section{DETERMINANTES INDIVIDUAIS E DE CONTEXTO DA SIMPATIA PARTIDÁRIA NA AMÉRICA LATINA}

\section{Julian Borba, Ednaldo Ribeiro, Yan Carreirão e Eder Rodrigo Gimenes}

Palavras-chave: Partidos; Sistemas partidários; Simpatia partidária; América Latina.

O contexto político latino-americano é marcado pela recorrência de frágeis vínculos programáticos e ideológicos entre eleitores e partidos, além de acentuada volatilidade eleitoral e níveis decrescentes de confiança política. A despeito desse cenário, os partidos continuam centrais ao funcionamento das democracias na região, assim como em regimes consolidados. Entendendo que um dos elementos centrais na dinâmica dos sistemas partidários é o vínculo existente entre eleitores e partidos, nosso objetivo é identificar as bases individuais e contextuais da manifestação de simpatia partidária entre os eleitores latino-americanos. Para tanto, construímos modelos de regressão hierárquica com dados individuais do Latin American Public Opinion Project (Lapop) e informaçôes dos contextos político e econômico nacionais. Os resultados apontam a preponderância da capacidade explicativa da idade da democracia diante de características individuais e nacionais (econômicas, políticas e partidárias).

\section{INDIVIDUAL AND CONTEXTUAL DETERMINANTS OF PARTY SYMPATHY IN LATIN AMERICA}

\section{Julian Borba, Ednaldo Ribeiro, Yan Carreirão e Eder Rodrigo Gimenes}

Keywords: Parties; Party systems; Party sympathy; Latin America.

The Latin American political context is marked by the recurrence of fragile programmatic and ideological links between voters and parties, as well as marked electoral volatility and decreasing levels of political trust. Despite this scenario, parties remain central to the functioning of democracies in the region, as well as in consolidated regimes. Understanding that one of the central elements in the dynamics of party systems is the link between voters and parties, our objective is to identify the individual and contextual foundations of party sympathy manifestation among Latin American voters. We propose hierarchical regression models with individual data from the Latin American Public Opinion Project (Lapop) and information from national political and economic contexts. The results point to the preponderance of the explanatory capacity of the democracy age in relation to individual and national characteristics (economic, political and partisan).

\section{LES DÉTERMINANTS INDIVIDUELS ET CONTEXTUELS DE LA SYMPATHIE PARTISANE EN AMÉRIQUE LATINE}

\author{
Julian Borba, Ednaldo Ribeiro, Yan \\ CarreirãoetEder Rodrigo Gimenes
}

Mots-clés: Partis politiques; Systèmes de partis; Sympathie partisane; Amérique Latine.

Le contexte politique latino-américain est marqué par des liens programmatiques et idéologiques qui, de façon récurrente, sont fragiles, ainsi que par uneforte volatilité électorale et des niveaux décroissants de confiance politique. Malgré ce scénario, les partis politiques demeurent centraux pour le fonctionnement des démocraties dans la région, ainsi que pour les régimes démocratiques consolidés. Notre objectif, face à la compréhension que l'un des éléments centraux dans la dynamique des systèmes de partis est la liaison existante entre les électeurs et les partis, est d'identifier les fondements individuels et contextuels de la manifestation de sympathie partisane parmi les électeurs latino-américains. Nous avons, pour autant, construit des modèles de régression hiérarchique avec des données individuelles du Latin American Public Opinion Project (Lapop) et des informations provenant des contextes politiques et économiques nationaux. Les résultats indiquent la prépondérance de la capacité explicative de l'âge de la démocratie face aux caractéristiques individuelles et nationales (économiques, politiques et partisanes). 


\section{ERRATA}

RBCS vol.33 no 97/2018

DOI: $10.1590 / 339700 / 2018 E R$

E-location: e339700ER

- Nos artigos: "O comitê de articulação federativa no governo Lula: os percalços da cooperação territorial"; "Marcuse crítico de Weber: a política no capitalismo tardio"; "Representação política: a virada construtivista e o paradoxo entre criação e autonomia"; "O pequeno investidor na bolsa brasileira: ascensão e queda de um agente econômico"; "Ciências humanas e neurociências: um confronto crítico a partir de um contexto educacional"; "A peculiaridade do maquiavelismo inglês: das origens ao século XVII"; "Internacionalização de micro, pequenas e médias empresas inovadoras no Brasil: desafios do novo paradigma de desenvolvimento"; "A luta pelo reconhecimento e o paradigma da dádiva: uma proposta de articulação teórica" e "Determinantes individuais e de contexto da simpatia partidária na América Latina", assim como nas resenhas: "Um acerto de contas com o judiciário argentino", "A imprevisibilidade democrática" e "Idle No More: sobre a mobilização indígena no Canadá", publicados na Revista Brasileira de Ciências Sociais, 2018, volume 33, número 97, cujos e-locations são respectivamente: e339703, e339704, e339705, e339710, e339702, e339706, e339708, e339709, e339711, e339715, e339716 e e339717, os prefixos do DOI estáo incorretos.

Onde se lia: "10.590"

Leia-se: "10.1590”. 